\title{
The secretory leukocyte protease inhibitor gene is a target of epidermal growth factor receptor action in endometrial epithelial cells
}

\author{
M C Velarde, S I Parisek, R R Eason, F A Simmen and \\ R C M Simmen \\ Arkansas Children's Nutrition Center and Department of Physiology and Biophysics, University of Arkansas for Medical Sciences, 1120 Marshall St, \\ Little Rock, Arkansas 72202, USA \\ (Requests for offprints should be addressed to R C M Simmen; Email: simmenrosalia@uams.edu)
}

\begin{abstract}
The over-expression of epidermal growth factor receptor (EGFR) and its ligands, epidermal growth factor (EGF) and transforming growth factor- $\alpha$, is a common feature of epithelial carcinomas and correlates with neoplastic progression. Secretory leukocyte protease inhibitor (SLPI), a member of the Kazal superfamily of serine anti-proteases, induces proliferation and promotes malignancy of epithelial cells and is expressed at high levels in multiple tumor types. In the present study, we have demonstrated that EGF increases SLPI expression in the human endometrial epithelial cell line Ishikawa in a dose- and time-dependent manner. We have shown that this effect of EGF occurs, in part, at the level of the SLPI promoter
\end{abstract}

and involves the MAP kinase signaling pathway. We have further shown that EGF promotion of cell proliferation, but not induction of cyclin D1 gene expression, involves SLPI. Our results suggest that the regulation of SLPI expression by EGFR ligand(s) may represent a 'feedforward' mechanism by which the enhanced proliferative and migratory properties of EGFR over-expressing cancer cells are sustained. Increased SLPI expression is likely an important component of altered EGFR signaling in human tumors and may have significant therapeutic implications in cancer progression.

Journal of Endocrinology (2005) 184, 141-151

\section{Introduction}

Secretory leukocyte protease inhibitor (SLPI), a $12 \mathrm{kDa}$ protein secreted by epithelial cells at mucosal surfaces and a member of the Kazal superfamily of serine protease inhibitors, inhibits the activities of elastase, cathepsin $G$, trypsin, and chymotrypsin via the carboxy-terminal portion of its two homologous cysteine-rich domains (Thompson \& Ohlsson 1986, Abe et al. 1991, Potempa et al. 1994). SLPI plays important and diverse roles in cellular immunity, inflammatory response, normal development, reproduction, and tissue growth (Hiemstra et al. 1996, Zhang et al. 1997, Denison et al. 1999, Song et al. 1999, Ashcroft et al. 2000, Wang et al. 2003). While the specific mechanisms underlying the multiple actions of SLPI remain largely unknown, increasing data have emerged to support the growth regulatory functions of this protease inhibitor. Over-expression of SLPI has been noted in human tumors and human carcinoma cell lines of ovarian, endometrial, respiratory tract, and neural origins (Koshikawa et al. 1996, Ameshima et al. 2000, Hough et al. 2001, Shigemasa et al. 2001, Westin et al. 2002). In endometrial clonal cell lines engineered to under-express
SLPI by forced expression of antisense SLPI mRNA, a direct linkage between cellular SLPI production and proliferation has been observed (Zhang et al. 2002a). In these cell lines, expression of SLPI was positively correlated with increased expression of the cell cycle progression factors cyclin D1 and proliferating nuclear antigen, and was inversely correlated with expression levels of the epithelial growth inhibitors, transforming growth factor- $\beta$ (TGF- $\beta$ ) and insulin-like growth factor-binding protein (IGFBP)-3, and of the tumor suppressor lysyl oxidase (Zhang et al. 2002a). A causal role for SLPI in the promotion of malignant behavior was also recently demonstrated in lung carcinoma cells stably transfected with mouse or human SLPI expression constructs (Devoogdt et al. 2003). This function of SLPI was attributed largely to its anti-protease activity, and was hypothesized to occur via SLPI inhibition of the elastase-mediated processing of the angiogenesis inhibitor endostatin (O'Reilly et al. 1997).

The epidermal growth factor (EGF) family of polypeptide hormones, which includes EGF, TGF- $\alpha$, amphiregulin, heparin-binding EGF-like growth factor, betacellulin, and epiregulin, regulates cell proliferation, 
motility, differentiation, and survival by modulating the expression of many cell growth-related genes that control cell cycle progression (Yarden 2001). This action is mediated by four members of the EGF receptor (EGFR) family of transmembrane receptor tyrosine kinases: ErbB-1, also called EGFR, ErbB-2 (also called HER2 or neu), ErbB3, and ErbB4. Auto-phosphorylation of these proteins upon binding of their ligands triggers the activation of multiple signaling cascades resulting in altered gene transcription (Alroy \& Yarden 1997, Hackel et al. 1999). The activation of particular signaling pathways (ras/raf/MAP kinase (MAPK), Akt/protein kinase B, and STAT) by activated EGFR is dependent on cell context (Zhong et al. 1994, Li et al. 2002, Schafer et al. 2004). The EGFR has been localized to the nucleus in many tissues and cell lines (Carpenter 2003), where it was demonstrated to transactivate cyclin D1 promoter (Lin et al. 2001). Although the significance of nuclear EGFR in the global expression of growth-regulatory genes is not well understood, the findings that EGFR and its ligands are commonly amplified and/or over-expressed in cancer cells (Jasonni et al. 1995, Niikura et al. 1996, Pfeiffer et al. 1997, Yarden 2001) support their patho-physiological roles in tumor initiation and progression.

In light of the coincident expression of SLPI, EGFR, and EGFR ligands in many tumors and carcinoma cell lines, we hypothesized that the induction of SLPI gene expression may represent one mechanism by which EGFR signaling enhances cell proliferation. In the present study we have shown that EGF increases SLPI gene expression in a dose- and time-dependent manner, that this occurs, in part, at the level of SLPI transcription, and that MAPK signaling, while involved in this inductive process, does not directly modulate SLPI promoter activity. We have further shown that EGF induction of Ishikawa cell proliferation, but not of cyclin D1 gene expression, is mediated by SLPI. Increased levels of SLPI may thus facilitate cell cycle progression by an as yet unknown mechanism, leading to the enhanced proliferative and migratory properties of EGFR over-expressing cancer cells.

\section{Materials and Methods}

\section{Materials}

Reagents, enzymes, and laboratory supplies were purchased from the following vendors: ULTRAhyb reagent from Ambion (Austin, TX, USA); restriction enzymes from Roche Molecular Biochemicals (Indianapolis, IN, USA); nick-translation kit from Amersham Pharmacia Biotech, Inc. (Piscataway, NJ, USA); $\left[\alpha_{-}{ }^{32} \mathrm{P}\right] \mathrm{dCTP}(3000$ $\mathrm{Ci} / \mathrm{mmol})$ and Biotrans nylon membranes $(0 \cdot 2 \mu \mathrm{m})$ from ICN Radiochemicals (Irvine, CA, USA); MAPK inhibitor (MKI) PD98059 from Cell Signaling Technology Inc. (Beverly, MA, USA); CellTiter 96 AQueous non- radioactive cell proliferation assay kit from Promega Corp. (Madison, WI, USA); cell culture media and supplies and TriZol reagent from Invitrogen (Carlsbad, CA, USA); antibiotic/antimycotic (ABAM) solution and glutamine from GIBCO (Carlsbad, CA, USA); and oligonucleotides from Integrated DNA Technologies, Inc. (Coralville, IA, USA). All other molecular reagents and solvents, when not listed, were purchased from Fisher Scientific (Pittsburgh, PA, USA).

\section{Cell culture}

The human endometrial epithelial carcinoma cell line Ishikawa (courtesy of Dr Bruce Lessey, Greenville, SC, USA) was routinely grown at $37^{\circ} \mathrm{C}$ in an atmosphere of $5 \% \mathrm{CO}_{2} / 95 \%$ air in minimal essential medium (MEM) supplemented with $10 \%(\mathrm{v} / \mathrm{v})$ fetal bovine serum (FBS) and $1 \%$ ABAM. Medium was replaced every 2-3 days, and cells were split after reaching confluence. For growth factor addition studies, cells were seeded in six-well plates at a density of $2 \times 10^{5}$ cells per well. Sub-confluent cells (80\%) were serum-starved for $24 \mathrm{~h}$ prior to treatment with vehicle (phosphate-buffered saline; PBS), recombinant human EGF (rhEGF) (R\&D Systems Inc., Minneapolis, MN, USA), recombinant human TGF- $\alpha$ (rhTGF- $\alpha$ ) (R\&D Systems) or recombinant human insulin-like growth factor-I (rhIGF-I; Upstate Biotechnology, Lake Placid, NY, USA) at the concentrations indicated (10$100 \mathrm{ng} / \mathrm{ml}$ ). All treatments were performed under low serum-containing medium (0.5\% FBS), unless otherwise indicated. For antibody treatments, goat anti-recombinant human SLPI IgG (R\&D Systems) and rabbit antirecombinant rat basic transcription element binding protein-1 (BTEB1) IgG (Zhang et al. 2002b) were added to cells at a dose of $2.5 \mu \mathrm{g} / \mathrm{well} 30 \mathrm{~min}$ prior to the addition of vehicle or rhEGF $(50 \mathrm{ng} / \mathrm{ml})$. For gene expression and protein studies, cells were collected 4,6 , or $24 \mathrm{~h}$ after treatment. For proliferation assays, cell density was evaluated $24 \mathrm{~h}$ after treatment. Images of cell densities were captured at $200 \times$ magnification using the Spot program, Version 4.0 (Diagnostic Instruments, Inc., Sterling Heights, MI, USA). Pictures were adjusted to $800 \times 600$ pixels using Adobe Photoshop, and the area occupied by cells (in $\mathrm{mm}^{2}$ ) was measured using the Scion Image program, Beta $4 \cdot 0 \cdot 2$ (Scion Corporation, Frederick, MD, USA). All experiments were repeated at least three times, with each experiment performed in triplicate.

\section{RNA isolation, Northern blot analysis and quantitative RT-PCR}

Total cellular RNA was prepared from Ishikawa cells using the TriZol reagent following the manufacturer's protocol. Total RNA (30 $\mu \mathrm{g} / \mathrm{sample})$ was electrophoresed in $1 \%$ agarose/formaldehyde gels in $1 \times 3-(\mathrm{N}-$ morpholino) propanesulphonic acid (MOPS) buffer and blotted onto BioTrans membranes using the TurboBlotting 
system (Schleicher \& Schuell, Keene, NH, USA). RNA was immobilized to the membranes by u.v. cross-linking for 90 s followed by baking at $80{ }^{\circ} \mathrm{C}$ for $25 \mathrm{~min}$. The pre-hybridization and hybridization of membranes with ${ }^{32}$ P-labeled human SLPI cDNA fragment (399 bp) using ULTRAhyb followed previously described protocols (Zhang et al. 2002a). Membranes were washed twice in $2 \times \operatorname{SSC}, 0 \cdot 1 \% \operatorname{SDS}$ and in $0 \cdot 1 \times \operatorname{SSC}, 0 \cdot 1 \% \operatorname{SDS}$ at $42{ }^{\circ} \mathrm{C}$ for $15 \mathrm{~min}$ each time to remove non-specifically bound probe. Resultant hybridization signals on X-ray films were quantified using the Alpha Imager 2000 documentation and analysis system (Alpha Innotech Co., San Leandro, CA, USA). To adjust for loading differences among samples, the membranes were stripped with $1 \%$ SDS at $90{ }^{\circ} \mathrm{C}$, and re-probed with ${ }^{32} \mathrm{P}$-labeled human glyceraldehyde-3-phosphate dehydrogenase (GAPDH) cDNA fragment (971 bp).

mRNA levels were also determined by real-time quantitative RT-PCR (qPCR). Total RNA was quantified and analyzed for integrity using the Agilent 2100 bioanalyzer and RNA 6000 NanoLabChip kit (Agilent Biotechnologies, Palo Alto, CA, USA). RNA samples were reverse-transcribed using random primers and a cDNA synthesis kit following the manufacturer's protocols (Perkin Elmer Applied Biosystems, Foster City, CA, USA). Each primer set was designed to flank an intron to prevent the amplification of genomic DNA, using PrimerExpress (Perkin Elmer Applied Biosystems). The forward and reverse primers respectively and resultant PCR product sizes (in parentheses) were: (a) human SLPI: 5'-GCTGTGGAAGGCTCTGGAAA-3' and 5'-TGCC CATGCAACACTTCAAG-3' (297 bp); (b) human cyclin D1: 5'-AATGACCCCGCACGATTT-3' and 5'ATGGAGGGCGGATTGGAA-3' (144 bp); (c) human p21 WAF1: 5'-CAGCGACCTTCCTCATCCAC-3' and 5'-GAGAAACGGGAACCAGGACA-3' (155 bp); and (d) human 18S: 5'-TCTTAGCTGAGTGTCCCGCG-3'

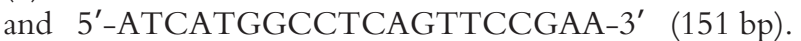
The latter was used to evaluate the efficiency and variability of the reverse transcription step. cDNA samples $(1 / 25$ of reverse transcription reaction) were amplified using the SYBR Green PCR Master Mix under conditions recommended by the manufacturer (Perkin Elmer Applied Biosystems): (a) preincubation at $50{ }^{\circ} \mathrm{C}$ for $2 \mathrm{~min}$; (b) DNA polymerase activation at $95{ }^{\circ} \mathrm{C}$ for $10 \mathrm{~min}$; and (c) 40 PCR cycles of $95^{\circ} \mathrm{C}$ for $15 \mathrm{~s}$ and $60{ }^{\circ} \mathrm{C}$ for $1 \mathrm{~min}$. Samples were assayed in duplicate using the ABI Prism 7000 detection system (Perkin Elmer Applied Biosystems). For each primer set, a standard curve was generated by serial dilution of pooled cDNAs. The threshold cycle, which represents the fractional cycle number where the fluorescent signal exceeds background was obtained for each reaction and used to calculate the mean RNA quantity. The melting points of all samples were routinely determined to confirm that the expected products were generated with minimal primer-dimer formation.

\section{Western blot analysis}

Cells were harvested and lysed by sonication in ice-cold lysis buffer (10 mM Hepes, $\mathrm{pH} 7 \cdot 9 ; 150 \mathrm{mM} \mathrm{NaCl} ; 1 \mathrm{mM}$ EDTA; 0.6\% IGEPAL CA-630 (Sigma Chemical Co.); $0.5 \mathrm{mM}$ phenylmethylsulfonyl fluoride) (Liu et al. 1997). Proteins were fractionated on SDS-polyacrylamide gels, and transferred to a nitrocellulose membrane. Immunoblotting was performed with rabbit polyclonal anti-human SLPI antibody $(1 \mu \mathrm{g} / \mathrm{ml})$ that was generously provided by Dr Pieter S Hiemstra (Leiden University, Leiden, The Netherlands). Horseradish peroxidase-conjugated goat anti-rabbit antibody (BioRad; diluted 1:2000 as per the manufacturer's instructions) and enhanced chemiluminescence reagent (Amersham Pharmacia Biotech, Arlington Heights, IL, USA) were used to detect immunoreactive bands followed by exposure to X-ray film.

\section{Transient transfection and luciferase assays}

Ishikawa cells were seeded at a density of $5 \times 10^{4}$ cells/ well in six-well dishes in serum-containing medium and incubated for $24 \mathrm{~h}$ to allow cells to adhere. Cells $(70 \%$ confluent) were transfected using lipofectAMINE reagent (Invitrogen) in OPTI-MEM I reduced serum medium (Invitrogen) for $6 \mathrm{~h}$ with SLPI reporter-promoter plasmids (containing 1385, 552, and 248 bp respectively of the $5^{\prime}$ regulatory region of the porcine SLPI gene) linked to the reporter plasmid luciferase E (pGL2-E; Promega) or empty vector plasmid (10 $\mu \mathrm{g}$ DNA/well) (Reed et al. 1996). After transfection, cells were incubated in serumcontaining medium for an additional $18 \mathrm{~h}$, and then transferred to low serum-containing (0.5\% FBS) medium with or without added rhEGF $(50 \mathrm{ng} / \mathrm{ml})$. The MKI PD98059 $(2 \mu \mathrm{M})$ was added $30 \mathrm{~min}$ prior to rhEGF treatment. In a number of experiments, $\beta$-galactosidase expression plasmid pSV-GAL (5 $\mu \mathrm{g} /$ well; Promega) was co-transfected with SLPI-LucE-reporter constructs to evaluate transfection efficiency. Luciferase activity (measured as relative light units; RLU) was measured in cell lysates using the Promega luciferase assay system and an MLX microtiter plate luminometer (Dynex Technologies, Inc., Chantilly, VA, USA). Two independent transfection experiments were performed, with each experiment carried out in triplicate $(n=6$ samples/treatment group). Protein concentration of extracts was determined by the Lowry method using bovine serum albumin as a reference standard. Results were normalized to the protein content of each sample and are presented as least square means \pm S.E.M.

\section{MTS cell proliferation assay}

Ishikawa cells were seeded at a density of $1.2 \times 10^{4}$ cells/well in 96-well culture plates in MEM containing $10 \% \mathrm{FBS}$, and $1 \mathrm{~h}$ later, were transferred to low serum 
(0.5\%)-containing MEM. After overnight incubation at $37^{\circ} \mathrm{C}$ in a humidified, $5 \% \mathrm{CO}_{2}$ atmosphere, cells were treated with rhEGF $(50 \mathrm{ng} / \mathrm{ml})$ in the presence or absence of anti-recombinant human SLPI IgG $(2.5 \mu \mathrm{g} /$ well) for another $24 \mathrm{~h}$. In vitro proliferation assay was performed using the MTS assay kit following the manufacturer's instructions (Promega). The reduction of MTS solution into formazan, which measures the numbers of metabolically active cells, was quantified by obtaining the absorbance at $570 \mathrm{~nm}$.

\section{Statistical analysis}

Data obtained from transfection, Northern, qPCR, and cell density assays were analyzed by one-way or two-way ANOVA, followed by inspection of all differences between pairs of means by the Tukey test. Differences were considered significant at $P \leq 0 \cdot 05$.

\section{Results}

EGF and TGF-a induce SLPI $m R N A$ expression in Ishikawa cells

To determine if events downstream of EGFR signaling pathways involve SLPI, the induction of SLPI mRNA expression by the EGFR ligands EGF and TGF- $\alpha$ was examined in Ishikawa cells. SLPI mRNA levels, normalized to those of the housekeeping gene GAPDH, were increased by both growth factors, with EGF showing a greater inductive effect than TGF- $\alpha$ when analyzed by two-way ANOVA $(P<0 \cdot 001)$ (Fig. 1). At the range of concentrations tested $(10,50$, and $100 \mathrm{ng} / \mathrm{ml})$, the effect of EGF was dose-dependent $(P<0 \cdot 05)$, in contrast to that of TGF- $\alpha \quad(P=0 \cdot 118)$. rhIGF-I at $100 \mathrm{ng} / \mathrm{ml}$ concentration did not affect SLPI mRNA levels in these cells (data not shown).

We next determined whether SLPI mRNA expression is decreased in cells in which EGFR signaling was inhibited. In this experiment, rhEGF was used because of its greater inductive effect on SLPI gene expression than rhTGF- $\alpha$ (Fig. 1). Since the ras/raf/MAPK pathway is a major signaling cascade involved in the proliferative activity of EGFR (Olayioye et al. 2000), Ishikawa cells were incubated with rhEGF $(50 \mathrm{ng} / \mathrm{ml})$ in the presence or absence of the MKI PD98059 $(2 \mu \mathrm{M})$. Cells were harvested $24 \mathrm{~h}$ after treatment, and analyzed for SLPI mRNA and protein. As shown in Fig. 2 (A and B), EGF increased SLPI mRNA abundance. Treatment of Ishikawa cells with EGF in the presence of MKI reduced the amounts of SLPI mRNA. The inhibitor alone had no effect on basal SLPI mRNA expression (Fig. 2A). The amounts of SLPI protein, which were increased by EGF, were also decreased in cells treated with EGF/MKI, consistent with the effect observed for mRNA (Fig. 2C). MKI alone had no effect on basal SLPI protein levels. The identity of the higher $\mathrm{M}_{\mathrm{r}}$ immunoreactive band is unclear at present, although we have previously reported the presence of a comparably sized protein $(\sim 16 \mathrm{kDa})$ with the same amino-terminal amino acid sequences as authentic SLPI (14 kDa) from the pig uterus (Badinga et al. 1999).

\section{EGF increases SLPI promoter activity}

To examine if EGF induction of SLPI gene expression occurred at the transcriptional level, luciferase reporter constructs containing 1385, 552, and 248 bp respectively of the $5^{\prime}$-flanking and regulatory region of the porcine SLPI gene (Reed et al. 1996) were transiently transfected into Ishikawa cells, which were then treated with rhEGF $(50 \mathrm{ng} / \mathrm{ml})$ for $24 \mathrm{~h}$. Previous studies have shown the porcine SLPI gene promoter to exhibit highest homology to human and mouse SLPI gene promoter sequences within the $248 \mathrm{bp}$ region most proximal to the translation initiation site, and less so in more upstream regions (Stetler et al. 1986, Reed et al. 1996, Kikuchi et al. 1998). The longest SLPI-reporter construct ( -1385 SLPI-LucE) had robust promoter activity in Ishikawa cells, and this was further increased (by at least 2.5-fold) with EGF $(P<0 \cdot 05)$ (Fig. 3A). Reporter constructs containing shorter regions of the SLPI promoter ( -552 SLPI-LucE; - 248 SLPILucE) showed basal activities that were comparable with those of the longest construct and were also inducible by EGF. Interestingly, the induction by EGF was greater with the -248 SLPI-LucE construct than with -552 SLPI-LucE $(P<0 \cdot 01)$ and -1385 SLPI-LucE $(P<0 \cdot 001)$ constructs respectively. Sequence analysis of the entire $1385 \mathrm{bp}$ promoter region using the Transfac6.0PublicDatabase (www.generegulation.com/pub/databases. html\#transfac) showed the presence of several regulatory motifs that can mediate the transcriptional activation of the SLPI promoter by EGF. In particular, we identified potential activated protein-1 (AP-1), serum-responsive element (SRE) and STAT-inducible element (SIE) motifs that were shown previously to mediate the regulation by EGF of various other gene promoters (Shi \& Teng 1996, Kloth et al. 2002, Li et al. 2003) in the SLPI promoter region (Fig. 3B).

To determine if the enhancement of SLPI promoter activity by EGF is mediated by MAPK signaling, the MKI PD98059 $(2 \mu \mathrm{M})$ was added to cells previously transfected with the -1385 SLPI-LucE construct $30 \mathrm{~min}$ prior to incubation in medium with or without added rhEGF for $24 \mathrm{~h}$. MKI did not affect the basal or the EGF-induced SLPI promoter activities (Fig. 3C).

\section{EGF-induced proliferation of Ishikawa cells involves SLPI}

In previous studies (data not shown), we found that rhEGF added at a range of concentrations $(10-100 \mathrm{ng} / \mathrm{ml})$ increased DNA synthesis in Ishikawa cells over that of 

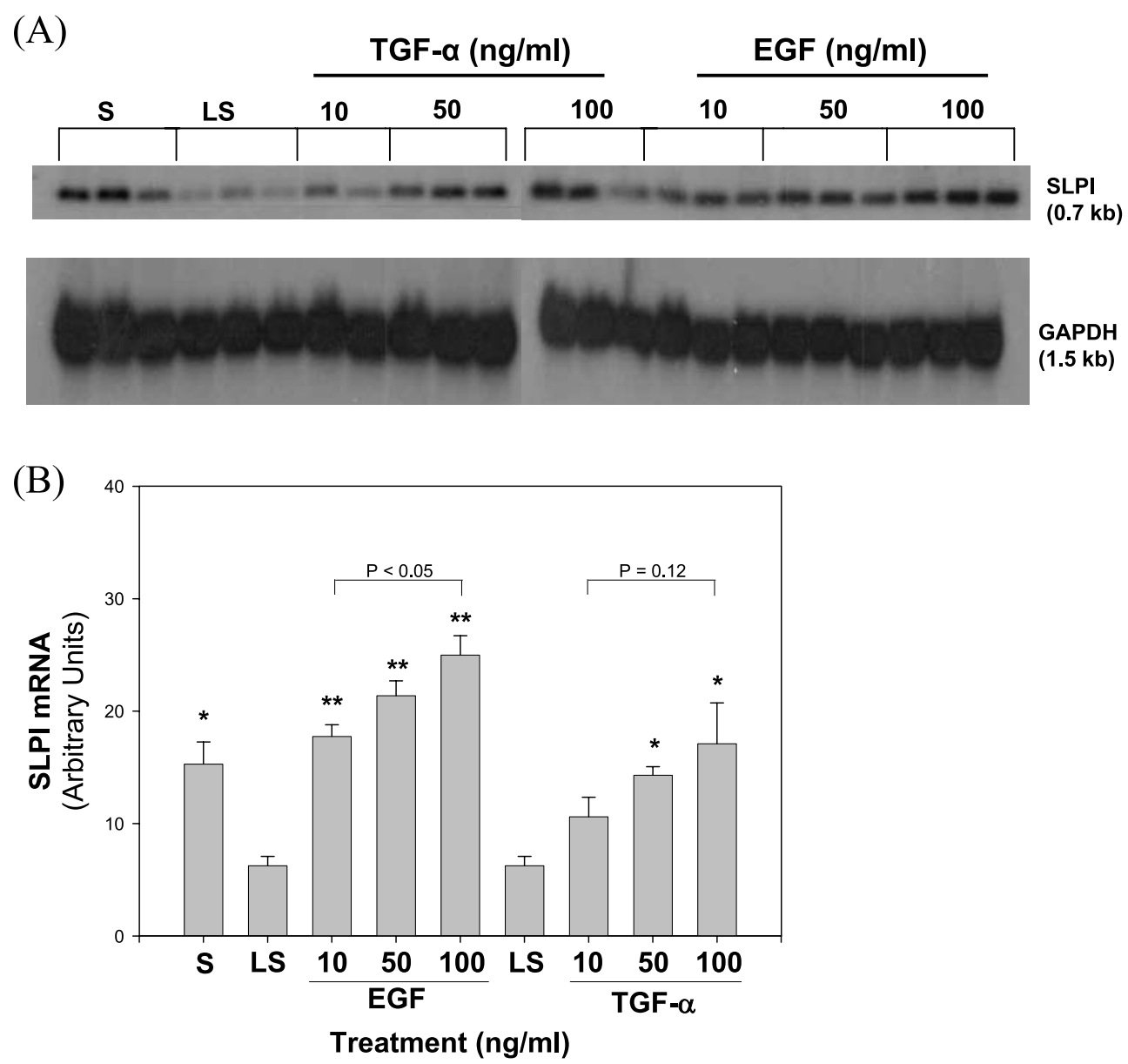

Figure 1 Regulation of SLPI mRNA levels by EGF and TGF- $\alpha$. Ishikawa cells were incubated in medium containing $10 \%$ FBS (S) or in low serum (0.5\% FBS)-containing medium (LS) with or without added rhTGF- $\alpha$ $(10-100 \mathrm{ng} / \mathrm{ml})$ or rhEGF $(10-100 \mathrm{ng} / \mathrm{ml})$ for $24 \mathrm{~h}$. (A) Total RNA was isolated and analyzed by Northern blot (30 $\mu$ g RNA/sample) using ${ }^{32}$ P-labeled SLPI or GAPDH cDNA fragments as probe. (B) The bar graphs (least square means \pm S.E.M.) represent the hybridization intensities of the SLPI transcript after normalizing to that of GAPDH. Differences between S and LS were evaluated by $t$-test. Two-way ANOVA (Tukey) was performed to evaluate the effects of treatment, dose, and dose $\times$ treatment interaction for EGF and TGF- $\alpha$. Asterisks indicate differences at $P<0.05\left(^{*}\right)$ and $\left.P<0.001{ }^{(*}\right)$ from LS.

untreated cells, as quantified by labeled thymidine incorporation. To determine if the proliferative activity of EGF is mediated, in part, by its induction of SLPI synthesis, we determined if the mitogenic signal of EGF was inhibited by the addition of anti-SLPI antibody. Ishikawa cells (seeded at $5 \times 10^{4}$ cells/well) in serum-containing MEM for $24 \mathrm{~h}$ were transferred to serum-free MEM to synchronize cell cycle stage. After $24 \mathrm{~h}$, cells were incubated in fresh low serum (0.5\%)-containing MEM supplemented with vehicle (PBS), rhEGF $(50 \mathrm{ng} / \mathrm{ml})$, anti-SLPI $\operatorname{IgG}$ $(2.5 \mu \mathrm{g} / \mathrm{well})$, or a combination of EGF and anti-SLPI IgG. Cells were examined under a light microscope $24 \mathrm{~h}$ later, and average cell density was measured for each treatment group by tracing the cell monolayer density in four randomly chosen fields $(200 \times$ magnification $) /$ culture plate. Results of three independent experiments are summarized in Fig. 4 (A and B). EGF increased cell density over those of control (untreated) cells. Addition of anti-SLPI antibody did not alter cell density, relative to controls. However, the overall cell density in cultures treated with EGF+anti-SLPI IgG was visibly diminished relative to those treated with EGF alone, and was comparable with control cells. An antibody against basic transcription element binding protein-1 (BTEB1), a protein unrelated to SLPI, did not affect basal cell density, when added alone or in combination with rhEGF (data not shown).

To validate the above results, Ishikawa cells were subjected to the same treatments and cell proliferation was measured $24 \mathrm{~h}$ later by the MTS assay. In preliminary 
(A)

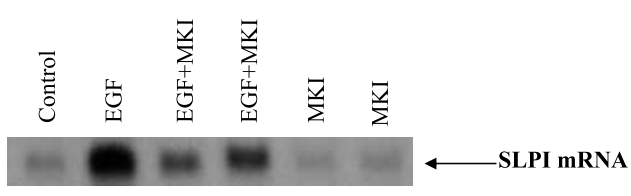

(B)

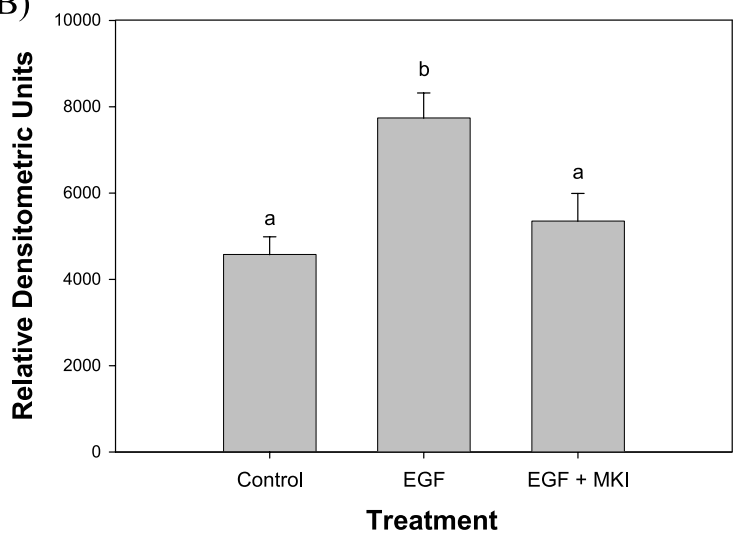

(C)

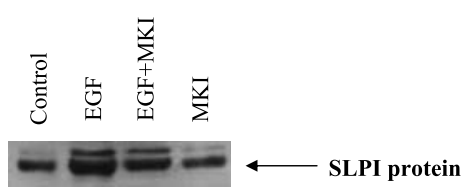

Figure 2 The MKI PD98059 inhibits EGF-induced SLPI expression. Ishikawa cells were incubated in low serum-containing medium $(0 \cdot 5 \% \mathrm{FBS})$ alone or in the same medium containing rhEGF $(50 \mathrm{ng} / \mathrm{ml})$ with $(\mathrm{EGF}+\mathrm{MKI})$ or without (EGF) added MKI PD98059 $(2 \mu \mathrm{M})$ for $24 \mathrm{~h}$. (A) Total RNA was isolated and analyzed for SLPI mRNA levels (30 $\mu$ g RNA/sample) by Northern blot analysis. (B) The bar graphs (least square means \pm S.E.M.) represent the hybridization intensities of the SLPI transcript after normalizing to that of GAPDH, in control cells and cells treated with EGF with and without added MKI. Results presented are from five independent experiments. Values with different subscripts are significantly different $(P<0 \cdot 05)$. (C) Cells were incubated in low serum-containing medium alone (Control) or in the presence of added rhEGF, rhEGF+MKI, and MKI alone. After $24 \mathrm{~h}$, cells were lysed (Materials and Methods) and equal amounts of protein (100 $\mu \mathrm{g} / \mathrm{sample})$ were separated by SDS-PAGE and transferred onto nitrocellulose membranes. Levels of SLPI protein were determined using a polyclonal antibody against anti-human SLPI. A representative Western blot is shown.

studies (data not shown), we confirmed that the spectrophotometer absorbance at $570 \mathrm{~nm}$ was directly proportional to the number of cells in the culture wells. Results from two independent experiments (where each experiment had $n=6$ culture wells/treatment) indicated that while EGF-treated cells had increased absorbance values over those of control cells $(0.756 \pm 0.009 \mathrm{vs}$ $0.602 \pm 0.003 ; P=0.002)$ cells with added anti-SLPI IgG had absorbance units comparable with control cells $(0 \cdot 655 \pm 0 \cdot 021$ vs $0 \cdot 602 \pm 0 \cdot 003 ; P=0 \cdot 55)$. Cells treated with EGF+anti-SLPI IgG had absorbance values $(0.695 \pm 0.008)$ that tended to be lower than those treated with EGF $(0 \cdot 756 \pm 0 \cdot 009 ; P=0 \cdot 07)$.

\section{Induction of cyclin D1 by EGF is independent of SLPI}

To determine if SLPI mediates EGF induction of cell cycle transit through an effect on cyclin D1 gene expression, we evaluated the temporal correspondence in the induction of cyclin D1 and of SLPI mRNA by EGF at 4 and $24 \mathrm{~h}$ after growth factor addition. EGF significantly increased $(P<0 \cdot 05)$ cyclin D1 mRNA levels over those for control (untreated) cells at $4 \mathrm{~h}$ post-treatment (Fig. 5, top panel). Cyclin D1 mRNA levels in cells treated with EGF for $24 \mathrm{~h}$ tended to remain higher $(P=0 \cdot 10)$ than in untreated cells, although these levels were lower $(P<0 \cdot 05)$ than those of 4-h EGF-treated cells. The inductive effect of EGF on SLPI mRNA levels was observed at $24 \mathrm{~h}$ and not at $4 \mathrm{~h}$ (Fig. 5, middle panel). The abundance of mRNA for p21 $1^{\text {WAF1 }}$, a cell cycle inhibitor, was also evaluated since a previous study has shown increased levels of $\mathrm{p} 21^{\text {WAF1 }}$ mRNA in EGFR null epidermal keratinocytes, suggesting inhibition by EGFR ligand of $\mathrm{p} 21^{\text {WAF1 }}$ gene expression (Woodworth et al. 2000). In Ishikawa cells, p21 mRNA levels did not change from those of untreated cells after incubation with EGF for 4 and $24 \mathrm{~h}$ (Fig. 5, bottom panel).

To further evaluate the relevance of SLPI on EGFinduced cyclin D1 gene expression, we next examined the temporal induction by EGF of cyclin D1 gene expression in the presence or absence of anti-SLPI antibody. Cells treated with EGF $(50 \mathrm{ng} / \mathrm{ml})$ for 4, 6, and $24 \mathrm{~h}$ had higher cyclin D1 mRNA levels than those of corresponding untreated cells or of cells incubated with anti-SLPI IgG (added at $2 \cdot 5 \mu \mathrm{g} /$ well) alone (Fig. 6). Anti-SLPI IgG did not affect basal or EGF-enhanced cyclin D1 gene expression at all incubation times.

\section{Discussion}

Results from this study support a model in which the transmission of the EGF/EGFR mitogenic signal in human Ishikawa endometrial epithelial cells involves the up-regulation of SLPI synthesis. Our data showed that: (a) EGFR signaling induced SLPI gene transcription, leading to increased levels of SLPI mRNA and protein; (b) this effect of EGF was mediated, in part, through the MAPK signaling pathway; and (c) EGF-stimulated increase in cell proliferation was mediated, in part, by SLPI. Although a stimulatory role for SLPI in cell proliferation and promotion of tumor progression has been reported previously (Zhang et al. 2002a, Devoogdt et al. 2003), the present study constitutes the first to link the mitogenic activities of SLPI and EGF in the uterine endometrium. Our findings are consistent with the reported high basal expression of SLPI in carcinoma and transformed cells and tissues 
(Shigemasa et al. 2001, Westin et al. 2002, Schlingemann et al. 2003) where over-expression of EGFR and/or its ligands has been similarly observed (Jasonni et al. 1995, Niikura et al. 1996, Pfeiffer et al. 1997).

The induction of SLPI gene expression and proliferation of human epithelial Ishikawa cells by EGF appears to be mediated, in part, by the MAPK signaling cascade. This is suggested by the findings that addition of the MKI PD98059 abrogated EGF-induced SLPI mRNA abundance and that the EGF-mediated increase in cell proliferation (measured by cell density and MTS assay) was diminished by anti-SLPI antibody. Our data are in agreement with a previous report that responsiveness of Ishikawa cells to EGF growth stimulation was lost with the mutation of the K-ras oncogene (Kato et al. 1998), a

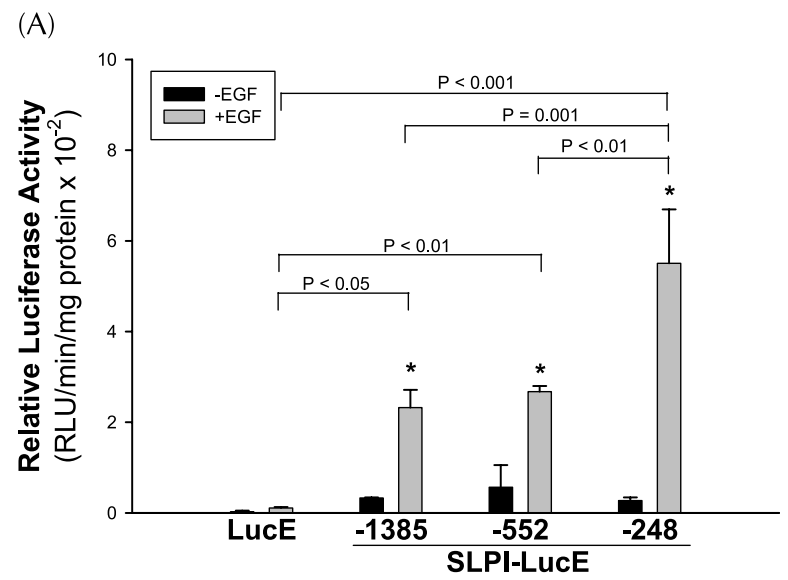

(B)

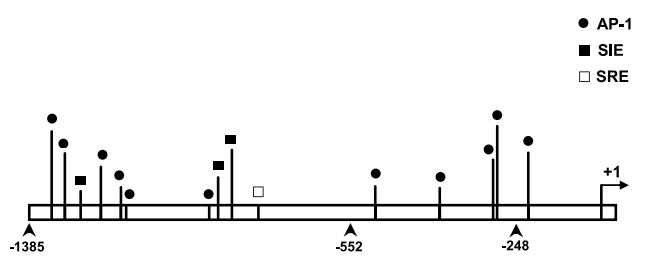

(C)

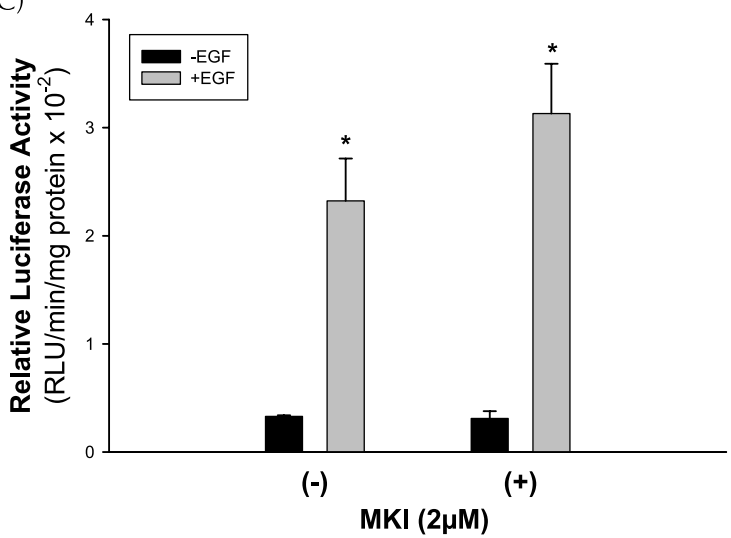

component of the ras/raf/MAPK signaling cascade. Although we cannot eliminate the involvement of the PI3K pathway, which signals through the activation of the downstream serine/threonine kinase Akt (Mendelsohn \& Baselga 2003), in the induction by EGF of SLPI gene expression reported here, the utilization of either pathway has been reported to be highly dependent on cell context (Martin et al. 2000, Kruger \& Reddy 2003, Shin et al. 2003). Indeed, the activation of Akt is largely linked to the anti-apoptotic function of EGFR (Grant et al. 2002). Interestingly, PD98059 failed to block EGF induction of SLPI promoter activity, suggesting that other ERKdependent mechanisms such as an increase in SLPI mRNA stability may also contribute to enhanced SLPI expression. SLPI mRNA transcripts have been reported to be relatively stable, consistent with the potential regulation of SLPI expression at the post-transcriptional level (Abe et al. 1991). Alternatively, the promoter constructs used here may not contain all the requisite regions for manifestation of an MKI response. The finding that the promoter activity of the shortest construct ( -248 SLPI-LucE) exhibited the most responsiveness to EGF induction, despite the presence of multiple consensus EGFresponsive motifs in the two longer constructs, suggests several possibilities including: (a) the EGF effect is mediated by non-consensus EGF-response element(s); (b) negative regulatory element(s) that mask the positive effects of EGF are present in the longer constructs; and (c) the upstream regulatory sequences of the porcine SLPI gene, which are distinct from those of the human (Stetler et al. 1986), do not contain the functional EGF response elements. However, the latter possibility is not supported by previous findings that TGF- $\alpha$ and, to a lesser extent, EGF stimulated SLPI gene expression in porcine uterine endometrium in vitro (Reed et al. 1998).

\footnotetext{
Figure 3 EGF increases SLPI promoter activity. (A) Ishikawa cells were transfected with luciferase promoter-reporter DNA constructs containing 1385, 552, and 248 bp of the porcine SLPI gene promoter with or without added rhEGF $(50 \mathrm{ng} / \mathrm{ml})$, as described under Materials and Methods. Reporter activity was normalized to protein content, and results are expressed as least square means \pm S.E.M. from two individual experiments, with each experiment carried out in triplicate. The asterisk $\left(^{*}\right)$ indicates significant difference $(P<0 \cdot 05)$ of EGF-treated from corresponding untreated ( - EGF) cells. Significant differences between treatment groups (indicated by brackets) were identified by two-way ANOVA. (B) The sequence of the $1385 \mathrm{bp}$ region of the porcine SLPI promoter was evaluated using the Transfac6.0-Public Database. The locations of putative motifs for AP-1, SIE, and SRE are indicated. $(+1)$ represents translation initiation site. (C) Cells transfected with the -1385 SLPI-LucE reporter construct were incubated in serum-free medium in the presence or absence of rhEGF $(50 \mathrm{ng} / \mathrm{ml}$ ) with or without added PD98059 (2 $\mu \mathrm{M})$. Results (least square means \pm S.E.M.) are from two individual experiments, with each experiment carried out in triplicate. The asterisk $\left(^{*}\right)$ indicates significant difference $(P<0 \cdot 05)$ from corresponding untreated cells.
} 
(A)

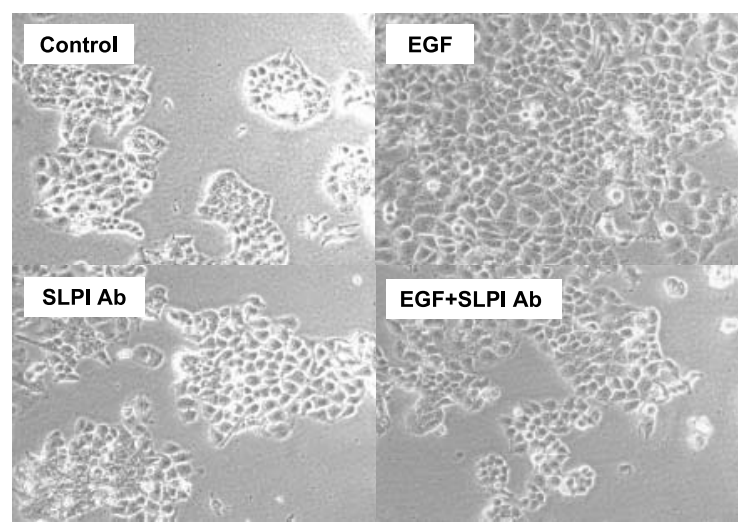

(B)

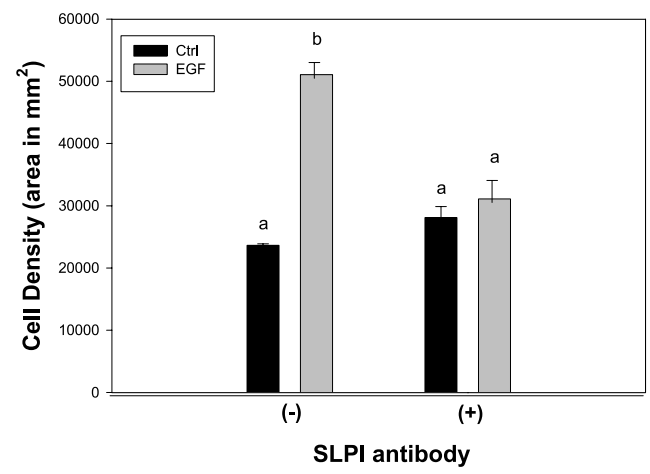

Figure 4 Effect of anti-SLPI antibody on Ishikawa cell proliferation. Ishikawa cells seeded at equal densities $\left(1 \times 10^{5} \mathrm{cells}\right)$ in $60 \mathrm{~mm}$ culture dishes were incubated in low serum (0.5\% FBS)-containing medium or in medium containing rhEGF (50 ng/ml), anti-SLPI antibody (Ab) (IgG fraction; $2 \cdot 5 \mu \mathrm{g} /$ well), or a combination of rhEGF and anti-SLPI antibody. Twenty-four hours later, cells were visualized under a light microscope. (A) A representative picture of resultant cell densities after the indicated treatments is shown. (B) Cell density for each treatment group was quantified as described under Materials and Methods, and cell surface areas (in $\mathrm{mm}^{2}$ ) are reported as least square means \pm S.E.M. Results are from three independent experiments. Means with different superscripts differ $(P<0 \cdot 05)$.

Our findings that anti-SLPI antibody can attenuate EGF induction of cellular proliferation provide strong support for the involvement of SLPI in growth control. On the other hand, the distinct temporal induction by EGF of cyclin D1 and SLPI gene expression, which occurred maximally at $4 \mathrm{~h}$ and $24 \mathrm{~h}$ respectively, and the inability of anti-SLPI antibody to inhibit the EGF-mediated increase in cyclin D1 gene expression are consistent with the notion that EGF induction of SLPI expression is not required to initiate cell proliferation. Since Ishikawa cells endogenously express SLPI, and addition of anti-SLPI antibody alone had no demonstrable effect on basal cyclin D1 gene expression or on basal cell proliferation status, the collective data suggest that SLPI may function in a supporting role, albeit a biologically important one, under conditions of persistent growth stimulus, whereby activation of additional growth signaling pathways may be initiated. Such is likely the case in epithelial carcinomas, which are characterized by over-expression of EGFR and/or corresponding ligands (Jasonni et al. 1995, Niikura et al. 1996, Pfeiffer et al. 1997) and increased levels of SLPI protein (Koshikawa et al. 1996, Ameshima et al. 2000, Hough et al. 2001, Shigemasa et al. 2001).

Studies by our group have demonstrated that SLPI can inhibit the expression of a number of anti-proliferative factors including IGFBP-3 and the ras inhibitor lysyl oxidase (Zhang et al. 2002a). SLPI has also been reported to prevent proteolysis of progranulin, a growth factor highly expressed in aggressive cancer cell lines and which mediates cell cycle progression via its induction of cyclins D and B (He \& Bateman 2003). Moreover, SLPI has been shown to increase the expression of hepatocyte growth factor in human lung fibroblasts, albeit the mechanism for this up-regulation remains unclear (Kikuchi et al. 2000). Taken together, these data suggest that cell proliferation mediated by EGF through induction of SLPI gene expression can result in the activation of distinct downstream pathways and demonstrate a versatile role for SLPI in growth-associated events.

Although our results suggest a linear pathway between EGF and cell proliferation via EGF induction of synthesized and secreted SLPI, the precise cellular signaling underlying SLPI modulation of cell proliferation remains unknown. A membrane receptor for SLPI has not been equivocally established (McNeely et al. 1997, Tseng \& Tseng 2000). Moreover, SLPI has been shown to bind to extracellular matrix components, including elastin, fibronectin, heparin, and the high molecular weight glycoprotein mucins (Kramps et al. 1981, Van-Seuningen et al. 1992, Llewellyn-Jones et al. 1994, Walter et al. 1996). Further, the induction by SLPI of cyclin D1 promoter activity (Zhang et al. 2002a) and its inhibition of the nuclear accumulation of nuclear factor- $\mathrm{KB}$ via maintenance of inhibitor of $\kappa B \beta$ levels (Lentsch et al. 1999) imply intracellular functions of the protein as well. Future studies to delineate the intra- and extra-cellular modes of SLPI signaling are warranted. Nonetheless, it is tempting to speculate, based on the results presented here, that SLPI may function as a key component of a positive 'feedforward loop' mechanism that confers a growth advantage to tumor cells.

Finally, it is of interest to note that, aside from their involvement in tumorigenesis, EGF and SLPI may also be linked to wound healing, a complex process requiring cell proliferation, migration, and differentiation. EGF has been reported to promote wound closure and epidermal regeneration (Pilcher et al. 1999, Gibbs et al. 2000). Similarly, mice null for the SLPI gene show impaired cutaneous wound healing (Ashcroft et al. 2000), that was corrected by administration of proepithelin, an epithelial growth factor 

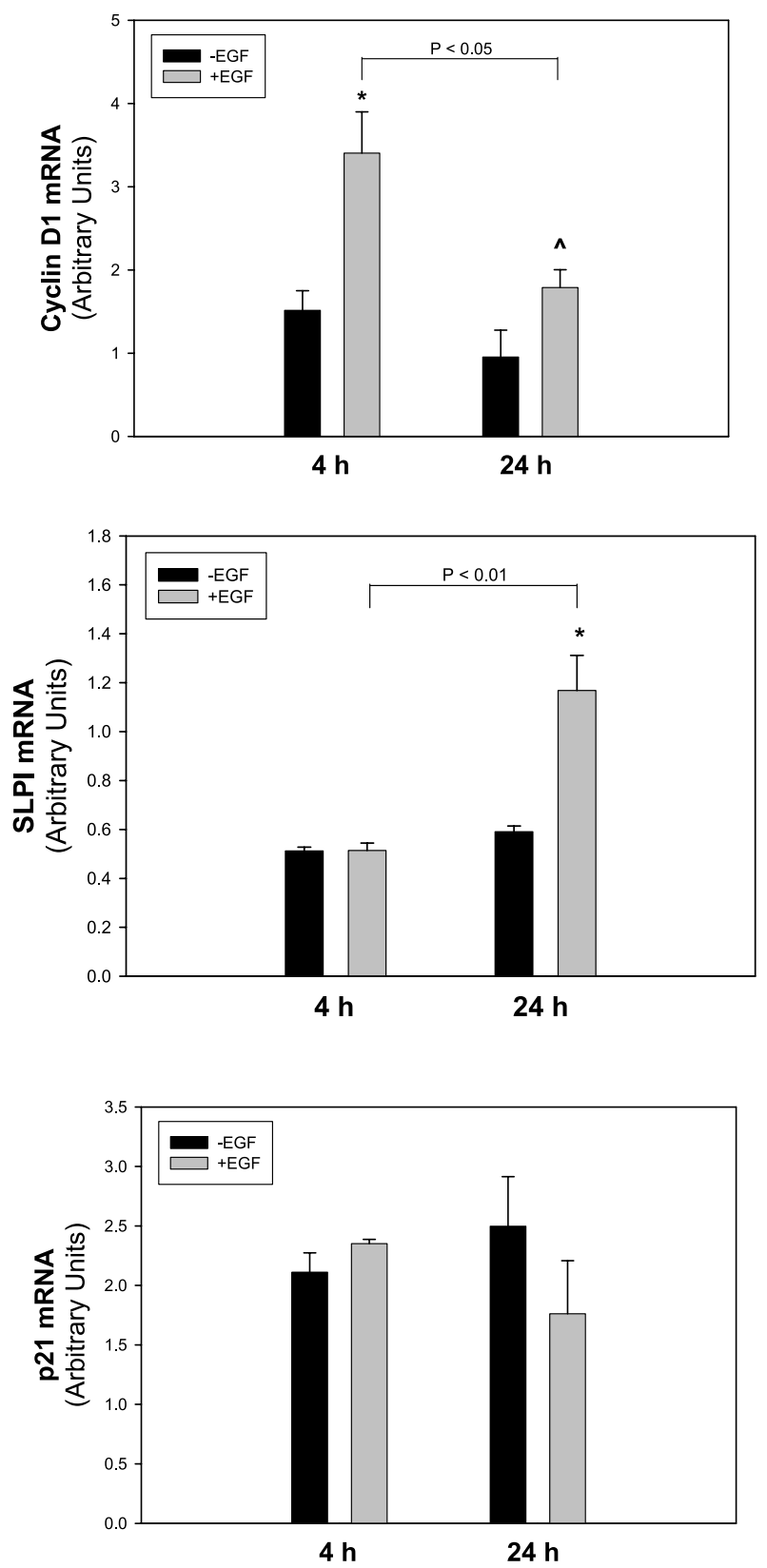

Figure 5 Temporal induction by EGF of cyclin D1, SLPI, and p21 WAF1 gene expression. Ishikawa cells were incubated in low serum $(0.5 \% \mathrm{FBS})$-containing medium with or without added rhEGF $(50 \mathrm{ng} / \mathrm{ml})$ for 4 or $24 \mathrm{~h}$, after which cells were harvested and analyzed for levels of cyclin D1 (top), SLPI (middle), or p21 $1^{\text {WAF1 }}$ (bottom) transcripts by quantitative RT-PCR, as described under Materials and Methods. Results (least square means \pm S.E.M.) were normalized to the transcript levels of 18S rRNA and are from three independent experiments. Significant differences between treatment groups (indicated by brackets) as a function of treatment duration were identified by two-way ANOVA. The asterisk $\left(^{*}\right)$ indicates significant difference $(P<0 \cdot 05)$ from corresponding control (untreated) cells. The symbol $\left({ }^{\wedge}\right)$ indicates tendency for significant difference $(P=0 \cdot 10)$ from corresponding control (untreated) cells.

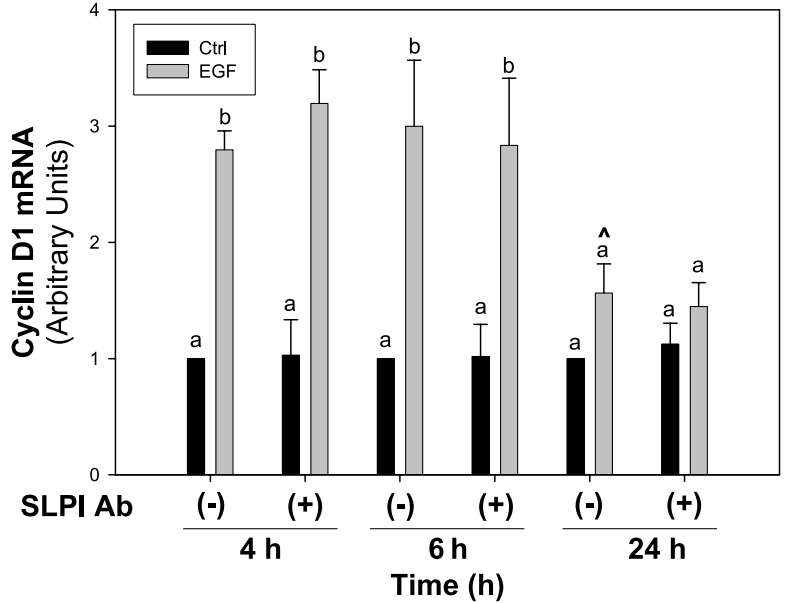

Figure 6 EGF induction of cyclin D1 expression is independent of SLPI. Ishikawa cells were treated with rhEGF or buffer (PBS) alone, as described in Fig. 1, with or without anti-SLPI antibody (Ab) (IgG fraction, $2.5 \mu \mathrm{g} /$ well). After 4, 6, and $24 \mathrm{~h}$, cells were harvested and analyzed for cyclin D1 transcript levels by quantitative RT-PCR, as described under Materials and Methods. Results from three independent experiments are shown and are expressed relative to transcript levels of control (untreated cells) after normalization of each transcript level to that of $18 \mathrm{~S}$. Means with different superscripts differ at $P<0.05$ (for $\mathrm{a}$ and $\mathrm{b}$ ) and at $P=0.07$ for â (relative to a).

whose activity is regulated by SLPI (Zhu et al. 2002). The up-regulation by EGF of SLPI expression in keratinocytes (Lai et al. 2004) was recently reported, albeit this study did not evaluate the level of EGF regulation.

In summary, the present results identify SLPI as an EGFR target gene. Given the recently described roles for SLPI in cell proliferation, tumor progression, and metastasis (Zhang et al. 2002a, Devoogdt et al. 2003), these findings suggest a novel pathway by which overexpression of EGFR and its ligands can lead to tumor progression and carcinoma. We propose that future studies of SLPI and possibly other serpin family members (Potempa et al. 1994) could provide significance to their potential pathophysiological actions in cancer progression and may lead to novel strategies for cancer treatment downstream of or in concert with those involving EGFR.

\section{Acknowledgements}

The authors thank Frank J Michel for expert technical assistance, Jason Blum and Lindsey Smith for help with cell culture, and Dr Pieter S Hiemstra for the gift of anti-human SLPI antiserum.

\section{Funding}

This study was supported by a grant from the National Institutes of Health (HD21961). There is no conflict of interest. 


\section{References}

Abe T, Kobayashi N, Yoshimura K, Trapnell BC, Kim H, Hubbard RC, Brewer MT, Thompson RC \& Crystal RG 1991 Expression of the secretory leukoprotease inhibitor gene in epithelial cells. Journal of Clinical Investtigation 87 2207-2215.

Alroy I \& Yarden Y 1997 The Erb signaling network in embryogenesis and oncogenesis: signal diversification through combinatorial ligand-receptor interactions. FEBS Letters 410 83-86.

Ameshima S, Ishizaki T, Demura Y, Imamura Y, Miyamori I \& Mitsuhashi H 2000 Increased secretory leukoprotease inhibitor in patients with nonsmall cell lung carcinoma. Cancer 89 1448-1456.

Ashcroft GS, Lei K, Jin W, Longenecker G, Kulkarni AB, Greenwell-Wild T, Hale-Donze H, McGrady G, Song XY \& Wahl SM 2000 Secretory leukocyte protease inhibitor mediates non-redundant functions necessary for normal wound healing. Nature Medicine 6 1147-1153.

Badinga L, Michel FJ \& Simmen RCM 1999 Uterine-associated serine protease inhibitors stimulate deoxyribonucleic acid synthesis in porcine endometrial glandular epithelial cells of pregnancy. Biology of Reproduction 61 380-387.

Carpenter G 2003 Nuclear localization and possible functions of receptor tyrosine kinases. Current Opinions in Cell Biology 15 143-148.

Denison FC, Kelly RW, Calder AA \& Riley SC 1999 Secretory leukocyte protease inhibitor concentration increases in amniotic fluid with the onset of labour in women: characterization of sites of release within the uterus. Journal of Endocrinology 161 299-306.

Devoogdt N, Hassanzadeh GG, Zhang J, Brys L, De Baetselier P \& Revets H 2003 Secretory leukocyte protease inhibitor promotes the tumorigenic and metastatic potential of cancer cells. PNAS $\mathbf{1 0 0}$ $5778-5782$.

Gibbs S, Silva Pinto AN, Murli S, Huber M, Hohl D \& Ponec M 2000 Epidermal growth factor and keratinocyte growth factor differentially regulate epidermal migration, growth, and differentiation. Wound Repair and Regeneration 8 192-203.

Grant S, Quiao L \& Dent P 2002 Roles of ERBB family receptor tyrosine kinases, and downstream signaling pathways, in the control of cell growth and survival. Frontiers of Bioscience 7 376-389.

Hackel PO, Zwick E, Prenzel N \& Ullrich A 1999 Epidermal growth factors receptors: critical mediators of multistep receptor pathways. Current Opinions in Cell Biology 11 184-189.

He Z \& Bateman A 2003 Progranulin (granulin-epithelin precursor, PC-cell-derived growth factor, acrogranin) mediates tissue repair and tumorigenesis. Journal of Molecular Medicine 81 600-612.

Hiemstra PS, Maassen RJ, Stolk J, Heinzel-Wieland R, Steffens GJ \& Djikman JH 1996 Antibacterial activity of antileukoprotease. Infection and Immunology 64 4520-4524.

Hough CD, Cho KR, Zonderman AB, Schwartz DR \& Morin PJ 2001 Coordinately up-regulated genes in ovarian cancer. Cancer Research 61 3869-3876.

Jasonni VM, Amadori A, Santini D, Ceccarelli C, Naldi S \& Flamigni C 1995 Epidermal growth factor receptor (EGF-R) and transforming growth factor alpha (TGF- $\alpha$ ) expression in different endometrial cancer. Anticancer Research 15 1327-1332.

Kato K, Ueoka Y, Kato K, Tamura T, Nishida J \& Wake N 1998 Oncogenic ras modulates epidermal growth factor responsiveness to endometrial carcinomas. European Journal of Cancer 34 737-744.

Kikuchi T, Abe T, Hoshi S, Matsubara N, Tominaga Y, Satoh K \& Nukiwa T 1998 Structure of the murine secretory leukoprotease inhibitor (Slpi) gene and chromosomal localization of the human and murine SLPI genes. American Journal of Respiratory Cell and Molecular Biology 19 875-880.

Kikuchi T, Abe T, Yaekashiwa M, Tominaga Y, Mitsuhashi H, Satoh K, Nakamura T \& Nukiwa T 2000 Secretory leukoprotease inhibitor augments hepatocyte growth factor production in human lung fibroblasts. American Journal of Respiratory Cell and Molecular Biology 23 364-370.
Kloth MT, Catling AD \& Silva CM 2002 Novel activation of STAT5B in response to epidermal growth factor. Journal of Biological Chemistry 277 8693-8701.

Koshikawa N, Nakamura T, Tsuchiya N, Isaji M, Yasumitsu H, Umeda M \& Miyazaki K 1996 Purification and identification of a novel and four known serine protease inhibitors secreted by human glioblastoma cells. Journal of Biochemistry 119 334-339.

Kramps JA, Franken C, Meijer CJL \& Djikman JH 1981 Localization of a low molecular weight protease inhibitor in serous secretory cells of the respiratory tract. Journal of Histochemistry and Cytochemistry 29 $712-719$.

Kruger JS \& Reddy KB 2003 Distinct mechanisms mediate the initial and sustained phases of cell migration in epidermal growth factor receptor-overexpressing cells. Molecular Cancer Research 1 801-809.

Lai J-Y, Borson ND, Strausbauch MA \& Pittelkow MR 2004 Mitosis increases levels of secretory leukocyte protease inhibitor in keratinocytes. Biochemical and Biophysical Research Communications 316 407-410.

Lentsch AB, Jordan JA, Czermak BJ, Diehl KM, Younkin EM, Sarma $\mathrm{V} \&$ Ward PA 1999 Inhibition of NF- $\mathrm{KB}$ activation and augmentation of I $\mathrm{I} B \beta$ by secretory leukocyte protease inhibitor during lung inflammation. American Journal of Pathology 154 239-247.

Li H, Velasco-Miguel S, Vass WC, Parada LF \& DeClue JE 2002 Epidermal growth factor receptor signaling pathways are associated with tumorigenesis in the Nf1:p53 mouse tumor model. Cancer Research 62 4507-4513.

Li J, Ma C, Huang Y, Luo J \& Huang C 2003 Differential requirement of $\mathrm{EGF}$ receptor and its tyrosine kinase for $\mathrm{AP}-1$ transactivation induced by EGF and TPA. Oncogene 22 211-219.

Lin S-Y, Makino K, Xia W, Matin A, Wen Y, Kwong KY, Bourguignon L \& Hung M-C 2001 Nuclear localization of EGF receptor and its potential new role as a transcription factor. Nature Cell Biology 3 802-808.

Liu SF, Haddad EB, Adcock I, Salmon M, Koto H, Gilbey T, Barnes PJ \& Chung KF 1997 Inducible nitric oxide synthase after sensitization and allergen challenge of Brown Norway rat lung. British Journal of Pharmacology 121 1241-1246.

Llewellyn-Jones CG, Lomas DA \& Stockley RA 1994 Potential role of recombinant secretory leucoprotease inhibitor in the prevention of neutrophil mediated matrix degradation. Thorax 49 567-572.

McNeely TB, Shugars DC, Rosendahl M, Tucker C, Eisenberg SP \& Wahl SM 1997 Inhibition of human immunodeficiency virus type 1 infectivity by secretory leukocyte protease inhibitor occurs prior to viral reverse transcription. Blood 3 1141-1149.

Martin MB, Franke TF, Stoica GE, Chambon P, Katzenellenbogen BS, Stoica BA, McLemore MS, Olivo SE \& Stoica A 2000 A role for Akt in mediating the estrogenic functions of epidermal growth factor and insulin-like growth factor I. Endocrinology 141 4503-4511.

Mendelsohn J \& Baselga J 2003 Status of epidermal growth factor receptor antagonists in the biology and treatment of cancer. Journal of Clinical Oncology 21 2787-2799.

Niikura H, Sasano H, Kaga K, Sato S \& Yajima A 1996 Expression of epidermal growth factor family proteins and epidermal growth factor receptor in human endometrium. Human Pathology 27 282-289.

Olayioye MA, Neve RM, Lane HA \& Hynes NE 2000 The ErbB signaling network: receptor heterodimerization in development and cancer. EMBO Journal 19 3159-3167.

O'Reilly MS, Boehm T. Shing Y, Fukai N, Vasios G, Lane WS, Flynn E, Birkhead JR, Olsen BR \& Folkman J 1997 Endostatin: an endogenous inhibitor of angiogenesis and tumor growth. Cell $\mathbf{8 8}$ $277-285$.

Perry JE, Grossman ME \& Tindall DJ 1998 Epidermal growth factor induces cyclin D1 in a human prostate cancer cell line. Prostate 35 $117-124$. 
Pfeiffer D, Spranger J, Al-Deiri M, Kimmig R, Fisseler-Eckhoff A, Scheidel P, Schatz H, Jensen A \& Pfeiffer A 1997 mRNA expression of ligands of the epidermal growth factor receptor in the uterus. International Journal of Cancer 72 581-586.

Pilcher BK, Dumin J, Schwartz MJ, Mast BA, Schultz GS, Parks WC \& Welgus HG 1999 Keratinocyte collagenase-1 expression requires an epidermal growth factor receptor autocrine mechanism. Journal of Biological Chemistry 274 10372-10381.

Potempa J, Korzus E \& Travis J 1994 The serpin superfamily of proteinase inhibitors: structure, function, and regulation. Journal of Biological Chemistry 269 15957-15960.

Reed KL, Badinga L, Davis DL, Chung TE \& Simmen RCM 1996 Porcine endometrial glandular epithelial cells in vitro: transcriptional activities of the pregnancy-associated genes encoding antileukoproteinase and uteroferrin. Biology of Reproduction $\mathbf{5 5}$ 469-477.

Reed KL, Blaeser LL, Dantzer V, Green ML \& Simmen RCM 1998 Control of secretory leukocyte protease inhibitor gene expression in the porcine periimplantation endometrium: a case of maternal-embryo communication. Biology of Reproduction $\mathbf{5 8}$ 448-457.

Schafer B, Gschwind A \& Ullrich A 2004 Multiple G-protein-coupled receptor signals converge on the epidermal growth factor receptor to promote migration and invasion. Oncogene 23 991-999.

Schlingemann J, Hess J, Wrobel G, Breitenbach U, Gebhardt C, Steinlein P, Kramer H, Furstenberger G, Hahn M, Angel P \& Lichter P 2003 Profile of gene expression induced by the tumour promoter TPA in murine epithelial cells. International Journal of Cancer 104 699-708.

Shi H \& Teng C 1996 Promoter-specific activation of mouse lactoferrin gene by epidermal growth factor involves two adjacent regulatory elements. Molecular Endocrinology 10 732-741.

Shigemasa K, Tanimoto H, Underwood LJ, Parmley TH, Arihiro K, Ohama K \& O'Brien TJ 2001 Expression of the protease inhibitor antileukoprotease and the serine protease stratum corneum chymotryptic enzyme (SCCE) is coordinated in ovarian tumors. International Journal of Gynecological Cancer 11 454-461.

Shin HS, Lee HJ, Nishida M, Lee MS, Tamura R, Yamashita S, Matsuzawa Y, Lee IK \& Koh GY 2003 Betacellulin and amphiregulin induce upregulation of cyclin D1 and DNA synthesis activity through differential signaling pathways in vascular smooth muscle cells. Circulation Research 93 302-310.

Song X, Zeng L, Jin W, Thompson J, Mizel DE, Lei K, Billinghurst RC, Poole AR \& Wahl SM 1999 Secretory leukocyte protease inhibitor suppresses the inflammation and joint damage of bacterial cell wall-induced arthritis. Journal of Experimental Medicine $\mathbf{1 9 0}$ $535-542$.

Stetler G, Brewer MT \& Thompson RC 1986 Isolation and sequence of a human gene encoding a potent inhibitor of leukocyte proteases. Nucleic Acids Research 14 7883-7896.

Thompson RC \& Ohlsson K 1986 Isolation, properties and complete amino acid sequence of human secretory leukocyte protease inhibitor, a potent inhibitor of leukocyte elastase. PNAS 83 6692-6696.
Tseng CC \& Tseng CP 2000 Identification of a novel secretory leukocyte protease inhibitor-binding protein involved in membrane phospholipids movement. FEBS Letters 475 232-236.

Van-Seuningen I, Aubert J-P \& Davril M 1992 Interaction between secretory leucocyte proteinase inhibitor and bronchial mucins or glycopeptides. Biochemical Journal 281 761-766.

Walter M, Plotnick M \& Schecter NM 1996 Inhibition of human mast cell chymase by secretory leukocyte proteinase inhibitor: enhancement of the interaction by heparin. Archives of Biochemistry and Biophysics 327 81-88.

Wang X, Li X, Xu L, Zhan Y, Yaish-Ohad S, Erhardt JA, Barone FC \& Feuerstein GZ 2003 Up-regulation of secretory leukocyte protease inhibitor (SLPI) in the brain after ischemic stroke: adenoviral expression of SLPI protects brain from ischemic injury. Molecular Pharmacology 64 833-840.

Westin U, Nystrom M, Ljungcrantz I, Eriksson B \& Ohlsson K 2002 The presence of elafin, SLPI, IL1-R $\alpha$ and STNF $\alpha$ R1 in head and neck squamous cell carcinomas and their relation to the degree of tumour differentiation. Mediators of Inflammation 11 7-12.

Woodworth CD, Gaiotti D, Michael E, Hansen L \& Nees M 2000 Targeted disruption of the epidermal growth factor receptor inhibits development of papillomas and carcinomas from human papillomavirus-immortalized keratinocytes. Cancer Research $\mathbf{6 0}$ 4397-4402.

Yarden Y 2001 The EGFR family and its ligands in human cancer signalling mechanisms and therapeutic opportunities. European Journal of Cancer 37 S3-S8.

Zhang D, Simmen RCM, Michel FJ, Zhao G, Vale-Cruz D \& Simmen FA 2002a Secretory leukocyte protease inhibitor mediates proliferation of human endometrial epithelial cells by positive and negative regulation of growth-associated genes. Journal of Biological Chemistry 277 29999-30009.

Zhang D, Zhang X-L, Michel FJ, Blum JL, Simmen FA \& Simmen RCM $2002 b$ Direct interaction of the Krüppel-like family (KLF) member, BTEB1, and PR mediates progesterone-responsive gene expression in endometrial epithelial cells. Endocrinology 143 62-73.

Zhang Y, DeWitt DL, McNeely TB, Wahl SM \& Wahl LM 1997 Secretory leukocyte protease inhibitor suppresses the production of monocyte prostaglandin $\mathrm{H}$ synthase-2, prostaglandin E2, and matrix metalloproteinases. Journal of Clinical Investigation 99 894-900.

Zhong Z, Wen Z \& Darnell JE Jr 1994 Stat3: a STAT family member activated by tyrosine phosphorylation in response to epidermal growth factor and interleukin-6. Science 264 95-98.

Zhu J, Nathan C, Jin W, Sim D, Ashcroft GS, Wahl SM, Lacomis L, Erdjument-Bromage H, Tempst P, Wright CD \& Ding A 2002 Conversion of proepithelin to epithelins: roles of SLPI and elastase in host defense and wound repair. Cell 111 867-878.

Received 3 September 2004

Accepted 20 September 2004

Made available online as an

Accepted Preprint 1 October 2004 